\title{
Front Matter: Volume 10452
}

, "Front Matter: Volume 10452," Proc. SPIE 10452, 14th Conference on Education and Training in Optics and Photonics: ETOP 2017, 1045201 (22 August 2017); doi: 10.1117/12.2285684

SDIE Event: 14th Conference on Education and Training in Optics and Photonics, SPIE. ETOP 2017, 2017, Hangzhou, China 


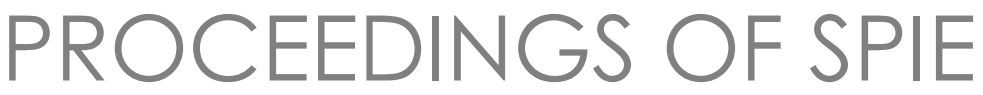

\title{
14th Conference on Education and Training in Optics and Photonics: ETOP 2017
}

\author{
Xu Liu \\ Xi-Cheng Zhang \\ Editors
}

29-31 May 2017

Hangzhou, China

Sponsored by

ICO-International Commission for Optics

IEEE-The Photonics Society

The Optical Society

SPIE

The Chinese Optical Society (China)

Organized by

CNSCOP_Chinese National Steering Committee of Optics and Photonics (China) - Optics Education Committee of the Chinese Optical Society (China) • Optical Society of Zhejiang Province (China) • Faculty of Information Technology, Zhejiang University (China) • College of Optical Science and Engineering, Zhejiang University (China) • State Key Laboratory for Modern Optical Instrumentation (China)

Published by

SPIE

Volume 10452

Part One of Two Parts 
The papers in this volume were part of the technical conference cited on the cover and title page. Papers were selected and subject to review by the editors and conference program committee. Some conference presentations may not be available for publication. Additional papers and presentation recordings may be available online in the SPIE Digital Library at SPIEDigitallibrary.org.

The papers reflect the work and thoughts of the authors and are published herein as submitted. The publisher is not responsible for the validity of the information or for any outcomes resulting from reliance thereon.

Please use the following format to cite material from these proceedings:

Author(s), "Title of Paper," in 14th Conference on Education and Training in Optics and Photonics: ETOP 2017, edited by Xu Liu, Xi-Cheng Zhang, Proceedings of SPIE Vol. 10452 (SPIE, Bellingham, WA, 2017) Seven-digit Article CID Number.

ISSN: 0277-786X

ISSN: 1996-756X (electronic)

ISBN: 9781510613812

ISBN: 9781510613829 (electronic)

Published by

SPIE

P.O. Box 10, Bellingham, Washington 98227-0010 USA

Telephone +1 3606763290 (Pacific Time) · Fax +1 3606471445

SPIE.org

Copyright (C) 2017 ICO, IEEE, OSA and SPIE

Copying of material in this book for internal or personal use, or for the internal or personal use of specific clients, beyond the fair use provisions granted by the U.S. Copyright Law is authorized by SPIE subject to payment of copying fees. The Transactional Reporting Service base fee for this volume is $\$ 18.00$ per article (or portion thereof), which should be paid directly to the Copyright Clearance Center (CCC), 222 Rosewood Drive, Danvers, MA 01923. Payment may also be made electronically through CCC Online at copyright.com. Other copying for republication, resale, advertising or promotion, or any form of systematic or multiple reproduction of any material in this book is prohibited except with permission in writing from the publisher. The CCC fee code is 0277-786X/17/\$18.00.

Printed in the United States of America.

Publication of record for individual papers is online in the SPIE Digital Library.

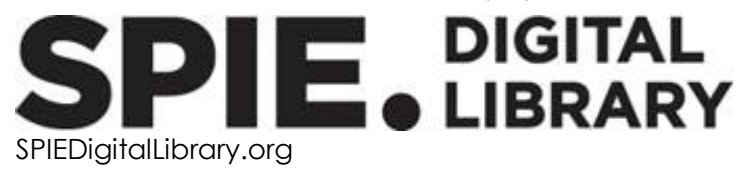

Paper Numbering: Proceedings of SPIE follow an e-First publication model. A unique citation identifier (CID) number is assigned to each article at the time of publication. Utilization of CIDs allows articles to be fully citable as soon as they are published online, and connects the same identifier to all online and print versions of the publication. SPIE uses a seven-digit CID article numbering system structured as follows:

- The first five digits correspond to the SPIE volume number.

- The last two digits indicate publication order within the volume using a Base 36 numbering system employing both numerals and letters. These two-number sets start with 00, 01, 02, 03, 04, 05, $06,07,08,09,0 A, O B \ldots$. OZ, followed by 10-1Z, 20-2Z, etc. The CID Number appears on each page of the manuscript. 


\title{
Contents
}

\author{
xV Authors \\ xxi Conference Committee \\ xxv Introduction
}

\section{Part One}

\section{CURRICULUM DEVELOPMENT IN OPTICS AND PHOTONICS EDUCATION I}

1045204 Demonstration of theoretical and experimental simulations in fiber optics course [10452-10]

1045205 Solar cell and photonics outreach for middle school students and teachers [10452-29]

1045206 The Master's program in Advanced Optical Technologies: an interdisciplinary, international and individual approach [10452-37]

1045207 Cathedral outreach: student-led workshops for school curriculum enhancement in non-traditional environments [10452-44]

NEW PEDAGOGICAL METHODS, TOOLS AND MODELS IN OPTICAL EDUCATION I

1045208 Near-field diffraction from amplitude diffraction gratings: theory, simulation and results [10452-7]

1045209 Why do I need to know this? Optics/photonics problem-based learning in the math classroom [10452-9]

10452 OA Towards the computer visualization of electrodynamics education for undergraduates major in optics [10452-17]

10452 OB New approaches in teaching laser engineering classes: modeling and building up a laser [10452-21]

EDUCATION AND TRAINING FOR MULTIDISCIPLINARY EDUCATION I

10452 OD Optical projects in the Clinic program at Harvey Mudd College [10452-39]

10452 OE Re-energizing enquiry among our young professionals [10452-43]

10452 OF Hierarchy curriculum for practical skills training in optics and photonics [10452-126] 
10452 OG Using polarization maintaining fibers for the purpose of a polarization multiplex [10452-19] INVITED SESSION I

10452 0J Solar powered rotorcraft: a multidisciplinary engineering challenge for undergraduate students (Invited Paper) [10452-49]

10452 OL Active learning in optics for girls (Invited Paper) [10452-237]

\section{CURRICULUM DEVELOPMENT IN OPTICS AND PHOTONICS EDUCATION II}

10452 OM Chinese national optical education small private online course system [10452-115]

10452 ON Enriching contents of optical courses with cutting-edge knowledge in nanophotonics [10452-142]

1045200 The Master level optics laboratory at the Institute of Optics [10452-144]

10452 OP Teaching practice and effect of the curriculum design and simulation courses under the support of professional optical software [10452-159]

\section{NEW PEDAGOGICAL METHODS, TOOLS AND MODELS IN OPTICAL EDUCATION II}

$104520 Q \quad$ Discussion and group work design in 020 teaching of applied optics: questions, strategies and extending [10452-30]

10452 OR Study and practice of flipped classroom in optoelectronic technology curriculum [10452-31]

10452 OS Modular and extensible lesson on fiber optics for youths [10452-42]

10452 OT A whole-process progressive training mode to foster optoelectronic students' innovative practical ability [10452-48]

10452 OW Student-centered and ability training-oriented curriculum reform in teaching Microcontroller Principles and Interface Techniques [10452-79]

10452 OY Teaching the concept of convolution and correlation using Fourier transform [10452-92]

$104520 Z$ An optoelectric professional's training model based on Unity of Knowing and Doing" theory [10452-99]

1045210 Why not serve an educational buffet for students? Blended learning in optics experimental education [10452-102]

1045211 The application of micro-lesson in optics teaching [10452-119] 
1045212 Visualization of polarization state and its application in optics classroom teaching [10452-127]

1045213 Exploration and practice in-class practice teaching mode [10452-131]

\section{LABORATORIES FOR OPTICS EDUCATION II}

1045215 Consequences of repeated discovery and benign neglect of non-interaction of waves (NIW) [10452-36]

1045216 Teaching stellar interferometry with polymer optical fibers [10452-61]

1045218 Optics simulations: a Python workshop [10452-95]

1045219 Observations and theoretical evaluations of color changes of traveling light beams caused by optical rotation phenomena in sugared water and their applications for educational purposes [10452-67]

10452 1B Photonics in nature: Yellowstone National Park in IR [10452-73]

10452 1C Demonstration and implications when $\mathbf{5 0 \%}$ beam combiners can behave as $0 \%$ or $100 \%$ reflector/transmitter inside some interferometers [10452-83]

10452 1D Interactive virtual optical laboratories [10452-93]

$104521 \mathrm{E}$ Optics education in an optometric setting [10452-104]

$10452 \mathrm{lF}$ Optical engineering: understanding optical system by experiments [10452-109]

$104521 \mathrm{G}$ The exploration and practice of the integrative and continuous optoelectronic practical teaching system [10452-117]

$10452 \mathrm{lH}$ An improved Michelson interferometer: smoothing out the rough spots for a more effective teaching tool [10452-147]

1045211 Optical circulator analysis and optimization: a mini-project for physical optics [10452-148]

$104521 \mathrm{~J}$ Introduction of optical tweezers in advanced physics laboratory [10452-153]

\section{EDUCATION AND TRAINING FOR MULTIDISCIPLINARY EDUCATION II}

$104521 \mathrm{~K}$ Light-based science and technologies and human civilization: an optical course for general education [10452-77]

$104521 \mathrm{M}$ Optoelectronic lessons as an interdisciplinary lecture [10452-111]

10452 iN Ball game watching theory in the teaching site [10452-118] 
1045210 Development of multidisciplinary nanotechnology undergraduate education program at the University of Rochester Integrated Nanosystems Center [10452-184]

DIGITAL AND INTERNET TECHNOLOGY FOR OPTICAL EDUCATION

10452 IP Integration of LCOS-SLM and LabVIEW based software to simulate fundamental optics, wave optics, and Fourier optics [10452-4]

$104521 Q \quad$ SiCloud: an online education tool for silicon photonics [10452-41]

10452 IR Learning in depth with the bespoke rubric-supported online poster presentation [10452-47]

10452 is Online course Geometrical Optics for undergraduate students [10452-53]

10452 1T Optical virtual experimental simulation platform: SeeLight [10452-82]

$104521 \mathrm{U} \quad$ Interactive teaching and learning with smart phone app in Optoelectronic Instruments course [10452-129]

$104521 \mathrm{~V}$ Experimental teaching and training system based on volume holographic storage [10452-255]

$104521 \mathrm{~W}$ MATLAB-aided teaching and learning in optics and photonics using the methods of computational photonics [10452-256]

10452 1X The PAD Class: a new paradigm for university classroom teaching [10452-263]

10452 IY Optical test course teaching practice on WeChat public platform [10452-264]

INTERNATIONAL EXCHANGE AND COOPERATION FOR OPTICAL EDUCATION

$104521 \mathrm{Z}$ Innovative training strategy for higher education: the photonics training platform at University of Bordeaux [10452-40]

1045220 Comparison and enlightenment of optical higher education between America and China [10452-50]

1045225 Curriculum design and German student exchange for Sino-German Bachelor program majored in optoelectronics engineering [10452-134]

1045226 Launching partnership in optics and photonics education between University of Rochester and Moscow Engineering Physics Institute NRNU MEPhI [10452-190]

1045227 German-Chinese cooperative Bachelor in engineering physics/optoelectronics [10452-226]

1045228 Open innovation at the Abbe School of Photonics [10452-230] 
1045229 The role of Chinese National Steering Committee of Optics and Photonics (CNSCOP) (Keynote Paper) [10452-121]

INVITED SESSION II

10452 2C Teaching physics and understanding infrared thermal imaging (Invited Paper) [10452-33]

10452 2D Engaging colleagues in active learning pedagogies through mentoring and co-design (Invited Paper) [10452-72]

\section{CURRICULUM DEVELOPMENT IN OPTICS AND PHOTONICS EDUCATION III}

10452 2F Photonics education development for electrical engineering students [10452-178]

$10452 \mathrm{2H}$ Has optics finally found its rightful place in physics curriculum in universities of Eastern Africa? [10452-186]

1045221 Quantum optics and nano-optics teaching laboratory for the undergraduate curriculum: teaching quantum mechanics and nano-physics with photon counting instrumentation [10452-189]

10452 2J Curriculum optimization of College of Optical Science and Engineering [10452-193]

NEW PEDAGOGICAL METHODS, TOOLS AND MODELS IN OPTICAL EDUCATION III

10452 2L Teach students Semiconductor Lasers according to their natural ability [10452-180]

10452 2N Flipping the Electromagnetic Theory classroom [10452-182]

\section{LABORATORIES FOR OPTICS EDUCATION III}

10452 2R Evolution of National University Students' Optical-Science-Technology competition in China [10452-166]

10452 2S Open source 3D printers: an appropriate technology for building low cost optics labs for the developing communities [10452-187]

10452 2T Cage structure application in photoelectric experiment and teaching [10452-191]

$104522 \mathrm{U}$ A simple student laboratory practice for the study of light scattering by cylindrical bodies [10452-212]

10452 2V Applied Electronics and Optical Laboratory: an optimized practical course for comprehensive training on optics and electronics [10452-218] 
10452 2W Engaging college physics students with photonics research [10452-5]

$104522 Y \quad$ Cultivation of students' engineering designing ability based on optoelectronic system course project [10452-128]

$104522 Z$ Training program developed for senior undergraduates majoring in optical communication [10452-154]

1045231 Teaching practice and reform of the cultivation of excellent engineer based on the idea of engineering education [10452-216]

\section{CURRICULUM DEVELOPMENT IN OPTICS AND PHOTONICS EDUCATION IV}

1045232 Exploration on teaching reform of theory curriculum for engineering specialties [10452-204]

1045233 Stereoscopic construction and practice of optoelectronic technology textbook [10452-219]

1045234 On the structural logic of curriculum system for the optical instrument major [10452-259]

1045235 Design and practice of a comprehensively functional integrated management information system for major construction [10452-261]

\section{Part Two}

NEW PEDAGOGICAL METHODS, TOOLS AND MODELS IN OPTICAL EDUCATION IV

1045236 New approaches in teaching spectroscopy technique and application classes: history, experiments and frontier lectures [10452-251]

1045237 Study of research-based teaching mode in the course of Geometric Optics and Optical Instruments [10452-252]

1045238 Research on the teaching method based on cultivating interest [10452-260]

1045239 IMl's teaching design, feedback system and its localization [10452-262]

104523 A A simple method for processing data with least square method [10452-267]

\section{LABORATORIES FOR OPTICS EDUCATION IV}

10452 3B Blue sun reflected from water: optical lessons from observations of nature [10452-250]

10452 3C A demonstration of particle duality of light [10452-254] 
10452 3D To make a further explanation on some questions about optical imaging using a light field camera [10452-265]

$104523 \mathrm{E}$ Teaching practice of the course of Laser Principle and Application based on PBL mode [10452-266]

$104523 \mathrm{~F}$ An optoelectronic detecting based environment perception experiment for primer students using multiple-layer laser scanner [10452-268]

TEACHING OF PHOTONICS FOR HIGH SCHOOL STUDENTS

10452 3H Research summer camp in photonics [10452-59]

1045231 Teaching basic concepts based on diffraction grating to basic primary diffraction education students [10452-60]

10452 3K Middle and high school teachers' implementation reflections of photonics and optics curriculum in a qualitative study [10452-258]

KEYNOTE SESSION II

10452 3L Bringing optics to Fab Labs in Europe (Keynote Paper) [10452-279]

POSTER SESSION

$104523 Q \quad$ LCoS-SLM technology based on Digital Electro-optics Plafform and using in dynamic optics for application development [10452-3]

$104523 R$ Simulation and visualization of fundamental optics phenomenon by LabVIEW [10452-6]

1045235 Exploration of offering photoelectric experimental general elective courses for college students of science and technology [10452-11]

10452 3V Photoelectric professional students in common universities cultivate way to explore under the background of professional certification [10452-16]

10452 3W Study on diversified cultivation orientation and pattern of optoelectronic major undergraduates [10452-22]

$104523 X$ The exploration and practice of integrated innovation teaching in the Applied Optics course [10452-24]

$104523 Y$ Teaching autonomy: turning the teaching evaluation of the Applied Optics course from impart knowledge to the new intelligent thinking [10452-25]

1045240 To promote the engineering innovative abilities of undergraduates by taking projects as the guidance and competitions as the promotion [10452-32] 
$1045241 \quad$ Remote-controlled optics experiment for supporting senior high school and undergraduate teaching [10452-38]

1045242 Exploration and practice of the cultivation of optoelectronic innovative talents based on the Students Innovation Training Program [10452-45]

1045243 Investigation, study and practice of optoelectronic MOOCs [10452-46]

1045244 Exploration and practice for engineering innovative talents training based on project-driven [10452-51]

1045245 Reform and practice for photoelectric specialty experimental teaching based on virtual simulation experiment plafform [10452-52]

1045246 The application of network teaching in applied optics teaching [10452-55]

1045247 The optical design of solar spectrograph [10452-56]

1045248 Student project of optical system analysis API-library development [10452-57]

1045249 Adaption of the Michelson interferometer for a better understanding of the temporal coherence in lasers [10452-62]

10452 4A PBL approach for undergraduate studies in light engineering [10452-63]

10452 4B Experimental instruction in photonics for high school students: approaches to managing problems faced [10452-66]

10452 4C An exploration of the biomedical optics course construction of undergraduate biomedical engineering program in medical colleges [10452-68]

10452 4D Design and implementation of a modular interactive labyrinth targeted for use in optical education [10452-76]

$104524 \mathrm{E}$ Effect of finite beam size on the spatial and spectral response of a Fabry-Perot interferometer [10452-78]

10452 4F Practical research on the teaching of Optical Design [10452-81]

10452 4G Cognition and thinking on Applied Optics course's reformation and innovation [10452-84]

$104524 \mathrm{H}$ Demonstration of wave optic in physics education [10452-88]

1045241 Exploration on the training mode of application-oriented talents majoring in optoelectronic information [10452-89]

$104524 J$ FDTD method and models in optical education [10452-94]

$104524 \mathrm{~K}$ Study on the depolarization of $\mathrm{CCl}_{4}$ Raman spectrum by the parameter of polarizer and analyzer [10452-96] 
$104524 \mathrm{~L}$ Exploration of multidimensional interactive classroom teaching for CCD principle and application course [10452-98]

$104524 M \quad$ Reform of experimental teaching based on quality cultivation [10452-100]

10452 4N The application and improvement of Fourier transform spectrometer experiment [10452-103]

1045240 Active learning in camera calibration through vision measurement application [10452-105]

10452 4P A modified rotating liquid optics method to measure the gravity acceleration [10452-106]

$104524 Q$ Study of the undergraduate student's innovation and entrepreneurship training strategy [10452-107]

10452 4R Curriculum system for experimental teaching in optoelectronic information [10452-110]

$104524 \mathrm{~T}$ Design and practice of a novel experiment teaching systems based on the optoelectric information chain [10452-113]

$104524 \mathrm{U}$ Capacity-oriented curriculum system of optoelectronics in the context of large category cultivation [10452-114]

$104524 \mathrm{~V}$ Project-oriented teaching model about specialized courses in the information age [10452-116]

$104524 \mathrm{~W}$ Study on the joint training mode of optical engineering master [10452-122]

$104524 \mathrm{X}$ The practice of problem-based investigative teaching reform in semiconductor physics course [10452-123]

$104524 \mathrm{Y}$ Experimental teaching reforms of optical fiber communication based on general education [10452-124]

$104524 Z$ Recent progress in holographic display technology [10452-125]

1045250 Improvement of the experimental content in Laser Principle and its Application [10452-138]

1045251 Pure study and experimental application of laser measurement for students in independent colleges [10452-139]

1045252 Exploration on practice teaching reform of Photoelectric Image Processing course under applied transformation [10452-140]

1045254 Practice and thinking on examination way reform of optoelectronic detection technology course [10452-143]

1045255 Effective approach to spectroscopy and spectral analysis techniques using Matlab [10452-146]

1045256 MOOC construction and application in professional degree postgraduate education: taking Introduction to Engineering Optics as an example [10452-149] 
1045257 Exploration on the course construction of ocean optics [10452-150]

1045258 Exploration on the reform of the science and engineering experiment teaching based on the combination with teaching and scientific research [10452-151]

10452 5A Magneto-optical Kerr effect studies with classical electromagnetic theory [10452-156]

10452 5C Micro- and nano-photonics course in Beijing Institute of Technology [10452-158]

10452 5D A practice course to cultivate students' comprehensive ability of photoelectricity [10452-162]

$104525 \mathrm{E}$ Exploration of teaching mode aiming at engineering training [10452-164]

$104525 \mathrm{~F}$ Integrated design course of applied optics focusing on operating and maintaining abilities [10452-165]

$104525 \mathrm{G}$ Assessment by psychophysical methods for design courses of optical discipline [10452-167]

$104525 \mathrm{H} \quad$ Exploration of optical classroom teaching by network platform [10452-168]

10452 5J Mobile internet and technology for optical teaching reform in higher education [10452-172]

$104525 \mathrm{~L} \quad$ Investigation on the learning interest of senior undergraduate students in optoelectronics specialty [10452-176]

$104525 \mathrm{M}$ Cultivating engineering innovation ability based on optoelectronic experimental platform [10452-177]

$104525 \mathrm{~N}$ The exploration on the reform of production practice for photoelectric specialty [10452-179]

1045250 Virtual simulation experiment in the course Laser Principles and Techniques for undergraduates [10452-183]

$104525 \mathrm{P}$ Digital education reform for improving interaction between students and instructors [10452-188]

10452 5R Research on pre-scientific concept of light in children's cognitive activity [10452-195]

$104525 S$ The research on teaching reformation of photoelectric information science and engineering specialty experiments [10452-196]

$104525 \mathrm{~T}$ Simulation with Python on transverse modes of the symmetric confocal resonator [10452-197]

$104525 \mathrm{U}$ An experiment teaching method based on the Optisystem simulation platform [10452-198]

$104525 X$ The construction of bilingual teaching of optoelectronic technology [10452-200] 
1045260 Reform and practice of optical coherence tomography (OCT) system-driven teaching for optoelectronic instrument principle and design [10452-206]

1045262 Analysis on an illusion unexpected occurred on a moving statue leaving in fact but approaching by environmental judgment [10452-208]

1045263 Cultivation mode research of practical application talents for optical engineering major [10452-209]

1045264 The reform of the teaching mode of Applied Optics curriculum and analysis of teaching effect [10452-210]

1045265 Fiber-optical sensor with intensity compensation model in college teaching of physics experiment [10452-211]

1045266 Virtual experiment of optical spatial filtering in Matlab environment [10452-213]

104526 A Undergraduate education for optical engineering in China under the multidisciplinary education background [10452-220]

10452 6B Create a good learning environment and motivate active learning enthusiasm [10452-221]

$104526 \mathrm{C}$ The hierarchical teaching method exploration for curriculum design of photoelectric discipline [10452-222]

10452 6D Research on teaching reform and practice of applied optics design experiment [10452-223]

$104526 \mathrm{E}$ Exploring in teaching mode of Optical Fiber Sensing Technology outcomes-based education (OBE) [10452-224]

10452 6F Innovation ability and innovation spirit in photoelectric comprehensive experiment teaching [10452-225]

10452 6G Experiment and application of soft $x$-ray grazing incidence optical scattering phenomena [10452-227]

$104526 \mathrm{H}$ Research of fiber optical faceplate defects segmentation based on improved watershed algorithm [10452-229]

1045261 Workshops on photonics and optoinformatics for school students at ITMO University [10452-231]

10452 6J Simulation teaching method in Engineering Optics [10452-232]

$104526 \mathrm{~K}$ Innovative research on the group teaching mode based on the LabVIEW virtual environment [10452-234]

10452 6M Research on Experiment-Guidance-Theory teaching mode in optics course [10452-236]

$104526 \mathrm{~N}$ Study on process evaluation model of students' learning in practical course [10452-238] 
$104526 \mathrm{P}$ Exploration on the matching between Optical Comprehensive Design Experiment and Washington Accord [10452-241]

$104526 \mathrm{Q}$ The value of art-oriented pedagogical approaches to the teaching of optics and photonics [10452-243]

$104526 \mathrm{R}$ The importance of pedagogical content knowledge in curriculum development for illumination engineering [10452-244]

1045265 Research on training model of the optoelectronic major university student's innovative ability under the guidance of TRIZ theory [10452-247]

$104526 \mathrm{U}$ A development optical course based on optical fiber white light interference [10452-253] 


\title{
Authors
}

Numbers in the index correspond to the last two digits of the seven-digit citation identifier (CID) article numbering system used in Proceedings of SPIE. The first five digits reflect the volume number. Base 36 numbering is employed for the last two digits and indicates the order of articles within the volume. Numbers start with 00, 01, 02, 03, 04, 05, 06, 07, 08, 09, 0A, 0B...0Z, followed by 10-1Z, 20-2Z, etc.

\author{
Abedin, Kazi Monowar, 08 \\ Adam, Aurèle, $3 \mathrm{M}$ \\ Adam, Jost, $1 Q$ \\ Adams, Rhys, 2D, 2W \\ Adamson, Per, 00 \\ Aleshchenko, Yury A., 26 \\ Alexander, Alonzo B., 05 \\ Alexeev, llya, OB \\ Ali, R., OL \\ Ammar, A., 18 \\ Andreeva, Natalia, 61 \\ Aramburu, Ibon, 4E \\ Arregui, L., 16 \\ Arrue, J., 49 \\ Ashraf, I., OL \\ Ayesta, I., 49 \\ Bai, Chunhe, 4T \\ Bai, Zijun, 31 \\ Bakholdin, Alexey, 1S, 4A \\ Beliaeva, Alina S., 4D \\ Berger, Andrew J., 2N \\ $\mathrm{Bi}$, Weihong, 4L, 6B, 6E \\ Bigelow, Nicholas P., 10 \\ Bougrov, Vladislav, 4A \\ Bowles, T. A., 3K \\ Brady, K. P., 3K \\ Butova, Daria $V ., 4 D$ \\ Buyanovskaya, Elizaveta, 3H \\ Cai, Huaiyu, 4V \\ Cai, Peijun, OW \\ Cai, Xuemei, $2 \mathrm{~F}$ \\ Cao, Binfang, 4O, 52 \\ Cao, Danhua, $2 Y$ \\ Cao, Yang, $2 \mathrm{~F}$ \\ Cao, Yiping, 6P \\ Carpenter, Amy, 1B \\ Carpenter, Logan, 1B \\ Cen, Zhaofeng, OM, OQ, 5G \\ Chen, Aiping, $4 \mathrm{X}$ \\ Chen, Daqing, 40 \\ Chen, Guoqing, 4W \\ Chen, Hai-bin, 50 \\ Chen, Jingjing, 4G \\ Chen, Lawrence R., $2 \mathrm{~W}$ \\ Chen, Shuyan, 6G \\ Chen, Wenjing, 6P \\ Chen, Xiaodong, 4V \\ Chen, Yanru, 5K \\ Chen, Yongxiang, 3A
}

Chen, YU, 3Y

Chen, Zhe, 4T

Chen, Zhenqiang, 4R

Chen, Zilun, 64

Cheng, Xiangai, 37, 5F, 64

Choong, Zhengyang, 4B

Choudhury, Debesh, OY

Choy, S. H., 41

Chu, Chen-Hsien, 3Q

Chuang, Chin-Jung, IN

Cormier, Eric, 12

Cui, Sheng, $2 Z$

Cui, Tingwei, 57

Cui, Yutong, IV

Dai, Xiang, 3F

D'Alessandris, Paul D., 10

Danner, Aaron J., OJ

Dantcaranov, Ruslan, 48

Deng, Qiansong, 5Q

DeVore, Peter T. S., 1Q

$\mathrm{Di}$, Hongwei, 4R, 4T

Dong, Liquan, 10

Dong, Qian-min, 6K

Dong, Yan-yan, 6K

Donko, Andrei L., 07

Donnelly, Judith F., 09

Donnelly, Matthew J., 09

Donnelly, Stephanie, 09

Du, Jihe, 4J

Duan, Chengfang, OT

Duan, Cunli, 5E

Dvoř́ák, F., OG

Eastman, Clarke K., $1 \mathrm{H}$

Egorov, Vladimir, $3 \mathrm{H}$

Eilenberger, Falk, 28

Ekimenkova, Alisa, 1S

Ezhova, Kseniia, 1S, 4A

Fan, Changjiang, 4F

Fan, Yansong, OA

Fei, Lanlan, 35

Feng, Jie, 47

Feng, Xiao-hua, 4N

Fu, Guangwei, 4L, 6B, 6E

Fu, Sihua, 43

Fu, Xinghu, 4L, 6B, 6E

Fu, Xiuhua, 3X

Fu, Yuegang, $1 Y$

Fu, Yun, 3D

Fuhrmann, Thomas, 25, 27 
Gao, En-duo, 4N

Gao, Jinkai, 6H

Gao, Lei, 40

Gao, Ling-Ling, 5A

Gao, Ming, 50

Gao, Minhao, OA

Gao, Shumei, 4W

Garshin, Aleksei, 1S

Ge, Baozhen, 29

Geiss, Reinhard, 28

Geng, Meihua, 37

Geng, Tao, 5T, 6D, 6G

Ghalila, H., 18

Gilchrist, Pamela O., 05, 3K

Gillis, Kendra, 1B

Gleim, Artur, 3H

Gong, Dawei, 3F

Gong, Hua-ping, 6C, 6K

Grable, L. L., 3K

Großmann, Jürgen, 06

Gu, Dawei, 4X

Gu, Jihua, 1M, 40, 44, 45

Guo, Chu Cai, ON, 2L

Guo, Jierong, 40

Guo, Shijun, 4C

Gwamuri, J., 25

Han, Yanling, 33

Hao, Qun, 10, $1 \mathrm{U}$

Harris, Wilson, 1B

Hasegawa, Makoto, 19

$\mathrm{He}$, Xingdao, $6 \mathrm{~S}$

He, Youwu, 60, 62

Helgert, Christian, 28

Henz, Martin, OJ

$\mathrm{Hu}$, Bin, $5 \mathrm{C}$

Hu, Feng, 56

Hu, Haojun, 04, OT, 42, 4M

$\mathrm{Hu}, \mathrm{YaO}, 10,1 \mathrm{U}$

$\mathrm{Hu}$, Zhangfang, $2 \mathrm{~F}, 4 \mathrm{U}$

$\mathrm{Hu}$, Zheng-Da, $4 \mathrm{~W}$

Huang, Jie, 6K, 6N

Huang, Yifan, 10, $1 \mathrm{U}$

Huang, YuJia, OP

Huang, Zhangchao, 31

Hueso, R., 16

Illarramendi, María Asunción, 16, 49, 4E

Ismagilov, Azat, 61

Ivanov, Vyacheslav, 48

Ivanova, Tatiana, 1S, 48

Jalali, Bahram, 1Q

Jantzen, Alexander, 07

Ji, Cheng, $4 \mathrm{~N}$

Ji, Feng, 4G

Ji, Yun Jing, 5U, 66, 6A, 6M

Jia, Hongzhi, 25, 4Q

Jiang, Cathy Y., $1 Q$

Jiang, Haili, 3C, 6U

Jiang, Hongying, 4X

Jiang, Lei, 4K

Jiang, Lingying, $5 \mathrm{G}$
Jiang, Tian, $5 \mathrm{~F}$

Jiang, Wenjie, OR

Jiang, Zhuqing, $1 \mathrm{~V}$

Jiang, Zongfu, 37

Jiao, Zheng, $5 \mathrm{H}$

Jim, K. L., 41

Jin, Shang-zhong, 32

Jin, Wa, 6B

Jin, $Y i, 5 A$

Jin, Yongxing, 6C

Jing, Xu-feng, 32

John, Pearl V., 07

Jones, S. Gregory, 6S

Kalinkina, Olga, 48

Kazadi Mukenga, B. Albert, $2 U$

Ke, Changjian, $2 Z$

Kochnev, Kirill A., 4D

Kolomoitcev, Vladimir S., 4D

Kong, Lingqin, 10

Konov, Vitaly I., 26

Kozhina, Anastasiia D., 4D

Kozlov, Sergei, 3H, $6 \mathrm{I}$

Krivtcova, Renata S., 4D

Kuang, Xiulin, $1 G$

Kuzmina, Tatiana, 61

Kyselák, M., OG

Lahmar, S., 18

Lai, Jiancheng, 66, 6M

Lajevardipour, Alireza, IR

Lakshminarayanan, V., 18

Lan, L., 4 Y

Lan, Zhigao, 5S

Lang, Xiao-ping, 50

Lei, Bing, 04, OR, 12, 42, 43, 4M

Leng, Yan-bing, 3V

Lenton, Kevin, 2D

Leung, C. W., 41

Li, Cheng, 5X, $6 \mathrm{G}$

Li, Chen-xia, 32

Li, Dahai, 6P

Li, Dangjuan, $5 \mathrm{M}, 5 \mathrm{~N}$

Li, Dun, 64

Li, Hongbin, $6 \mathrm{~J}$

Li, Hui, 60, 62

Li, Jianqi, 52

$L i$, Jingping, $2 Y$

Li, Kun, 5P

Li, Kun, 65, 6G

Li, Lei, 47

Li, Lin, 46

Li, Ling, $4 \mathrm{Z}$

Li, Qingbo, 5X, 6U

Li, Xiang, 55

Li, Xiaoqin, 4O, 52

$\mathrm{Li}$, Xiaotong, OM, OQ, IK, 5G

Li, Xiaoyan, $1 \mathrm{~W}$

Li, Xiufang, 1N, 2T

Li, Yan, 4T

Li, Yang, 34

Li, Ying, 57 
Li, Yongliang, 3E

Li, Yuanjie, 5Q

Li, Yuxiang, 5T

Li, Zhen, 4T

Li, Zhenhua, $5 \mathrm{U}, 6 \mathrm{M}$

Li, Zhifang, 60, 62

Liang, Binming, $4 Q$

Liang, Pei, 6C, 6K, 6N

Liang, Yiyong, $\mathrm{OW}$

Lin, Xiaogang, 4J

Lin, YuanFang, OF, OM, OP, 2R

Lin, Zhili, IW

Lindner, Gerhard, 27

Liu, Aimei, 4H, 4

Liu, Changqing, 4O, 52

Liu, Chan-lao, $5 \mathrm{M}, 5 \mathrm{O}$

Liu, Dongmei, 3X, 3Y, 46

Liu, He, $1 T$

Liu, Jing, $0 \mathrm{~A}$

Liu, Juan, 5C

Liu, Ken, ON, 2 L

Liu, Lishuang, 5D

Liu, Ming, 10

Liv, Qiang, 6B

Liv, S., 4 Y

Liu, Shugang, 12, 1N, 2T

Liu, Wangyun, $5 \mathrm{E}$

Liu, Wei, 04, OR, 12, 42, 43, 4M

Liu, Xiangdong, OF, OM, OQ, 29, 2R

Liu, $X U, O F, O M, 29,2 R$

Liu, Xuan, 1D

Liu, Yang, 5D

Liu, Yu, 2F

Liu, Yuankun, 6P

Liu, Yuling, OW, 35

Liu, Zhe, 51

Liu, Zhihai, 3C, 6D

Liv, Zhijian, 4G

Liu, Zhi-min, $4 \mathrm{~N}$

Liu, Zhiying, 1Y, 3W, 63

Lonappan, Cejo Konuparamban, $1 Q$

Lou, Jun, 32

Lu, Cunlian, 6D

Lu, Qieni, 6J

Lu, Yongle, 11

Lujua, Mikel, 4E

Lukishova, Svetlana G., 10, 26, 2I, 3H

Luo, Yuan, 11, 2F, 4U, 5V

Luo, Yunhan, 4R, 4T

LV, Beibei, 3E

LV, Hao, 4H, 4I

LV, Pin, IT

Lv, Qingsong, 44, 45

LV, Weige, $5 \mathrm{G}$

LV, Xian-Kui, 47

LV, Yong, 50, 55, 5D

Lyamets, Dmitry A., 4D

Lyu, Bo-Han, 1P, 3Q

Lyu, Bohan, 3R

Lyu, Jie, 4C
Ma, Kun, $5 \mathrm{H}$

Ma, Rui-Can, 5A

Mabiala Masiala, Toto, $2 U$

Madariaga, Gotzon, 4E

Majdi, Y., 18

Mak, C. L., 41

Mao, Xuefeng, 11

Mauroner, Oliver, 28

Melnik, Maksim, 3H

Meng, Hao, 50

Meng, Ting, 6D

Meng, Xiang-Yue, 47

Möllmann, Klaus-Peter, 2C

Monroy-Ramírez, F. A., 3l

Mu, Bing, 57

Ning, YU, 5F, 64

Niu, Chun-hui, 50, 5D

Niyibizi, Alphonse, $2 \mathrm{H}$

Nolte, Stefan, 28

Nugent, Paul W., 1B

Oberlé, Jean, $1 \mathrm{Z}$

Orekhova, Maria K., 4D

Pan, Wen-Qiang, 47

Pang, Guangning, 3A

Pearce, Joshua M., $2 S$

Peng, Baojin, 4F

Peng, Z. M., 4Y

Pertsch, Thomas, 28

Pflaum, Christoph, OB

Phuku Phuati, Edmond, $2 U$

Piao, Mingxu, 46

Pompea, Stephen M., 6Q, 6R

Posner, Matthew T., 07, OS

Pu, Jixiong, $1 \mathrm{~W}$

Putnam, Nicole M., $1 \mathrm{E}$

Qi, Jing, 5U, 66, 6A, 6M

Qi, Jin-quan, 4N

Qi, Liqun, 3A

Qin, Shiqiao, 0N, 0Z, 29

Qiu, Yishen, 62

Rahman, S.M. Mujibur, 08

Ravagli, Andrea, 07, 0S

Regens, Nancy L., 6Q

Ren, Zhijun, 4F

Resnick, J., 31

Romanova, Galina, is

Romanova, Maria, 48

Roychoudhuri, ChandraSekhar, OE, 15, 1C

Saitgalina, Azaliya K., 4D

Sanchez-Lavega, A., 16

Sang, Tian, 4W

Sazonenko, Dmitry, is

Scharf, Toralf, IF

Scherrer, Bryan, 1B

Schmauss, Bernhard, 06

Schmidt, Michael, OB

Schmidt, Titania A. R., 6S

Schreiner, Rupert, 25, 27

Seebaver, Gudrun, 25, 27

Shaw, Joseph A., 1B, 3B 
Shen, Chang-yu, 32

Shen, Hanxin, 31

Shen, Tao, 54

Shen, Wei-min, 32, 6N

Shen, Zhonghua, 66

Shevchenko, Denis N., 4D

Shi, Jianhua, 04, OR, 12, 42, 43, 4M

Shi, Lixia, 34

Shi, Yan, 32

Shi, Yaocheng, 29

Shu, Shuangbao, 4G

$\mathrm{Si}, \mathrm{Ke}, 1 \mathrm{~K}$

Si, Lei, 20

Šimák, P., OG

Smirnova, Irina, 4A

Song, Peng, 4P, 58

Song, Yang, 5U, 66, 6M

Soper, Nathan, 07

Stepanenko, Maksim A., 4D

Su, Liping, 65, 6G

Sui, Guorong, 4Q

Sun, Binchao, 35

Sun, Cai-xia, 6K

Sun, Chan, 1V

Sun, Peng, 5X, 6F

Sun, Qiuhua, 3C, 6U

Sun, Quan, $1 T$

Sun, Weimin, 6D

Sun, Yan-jun, 3V

Suzuki, Kenneth M., 6S

Tan, Ailing, 4L

Tang, Jieyuan, 4T

Tang, Qiuyan, $1 T$

Tao, Keyu, $4 Z$

Tao, Shen, 35

Teo, Brian Shohei, 0J

Tian, Qingguo, 4V

Tokumitsu, Seika, 19

Tolstoba, Nadezhda D., 1S, 4D

Tong, Amy S. K., OS

Tong, Chengguo, 6D

Trifonov, Oleg, is

Tsai, Chun-Wei, 1P, 3Q

Urbach, Paul, 3M

van Putten, Lieke D., 07

Varadharajan, S., 18

Vieules, Marie Bénédicte, 12

Vlček, Č., OG

Vollmer, Michael, 1B, 2C, 3B

Voznesenskaya, Anna, 1S, 4A

Walker, Constance E., 6R

Wan, Nan, 4J

Wan, Shengpeng, 6S

Wan, Yuhong, $1 \mathrm{~V}$

Wan, Zhujun, 11

Wang, Chen, $1 P, 3 Q$

Wang, Chunyan, $3 \mathrm{~A}$

Wang, Chunyong, 66

Wang, Dexing, 6F

Wang, Fengli, 4K
Wang, Gang, $1 \mathrm{~J}$

Wang, Huili, 33

Wang, Jicheng, $4 \mathrm{~W}$

Wang, Jinjiang, 4V

Wang, Kaiwei, 1K, 2J, 2R, 2V

Wang, Lan-lan, 4N

Wang, Lei, 4X

Wang, Li, 3V

Wang, Liqiang, OW

Wang, Luning, $4 \mathrm{~N}$

Wang, Mingquan, $6 \mathrm{H}$

Wang, $\mathrm{Na}, 5 \mathrm{M}$

Wang, Ning, 25, 27

Wang, Qing Hua, 5U, 66

Wang, Qing, 6S

Wang, Ran, 6D

Wang, Rui, 20

Wang, Rui, 3F

Wang, Shifeng, 3F

Wang, Siqi, 3E

Wang, Wei, 04, 12, 42, 4M

Wang, Xianchun, $4 \mathrm{O}$

Wang, Xiaofeng, 6F

Wang, Xiaolin, 04

Wang, Xiaoping, OF, OM, OW, 2J, 2R, 2V, 35

Wang, Xing-shu, OZ, 56

Wang, Yan, 11

Wang, Yi, 4V, 6J

Wang, Ying, $1 \mathrm{G}$

Wang, Zefeng, 37

Wang, Zhanshan, 4K

Wang, Zhe, IV

Wei, Jun, 6P

Weiss, William, 1B

Wen, Tingting, 39

Weng, Lingdong, 4J

Wick, Michael, 27

Wong, Nicholas H. L., 07, OS

Wood, Andrew, IR

Wu, Bo, 5P

Wu, Dan, $1 M$

Wu, Di, 40

Wu, Gaojian, 4X

Wu, Ling-ling, 50

Wu, Maocheng, 1M, 44, 45

Wu, Shenjiang, $5 \mathrm{M}, 5 \mathrm{~N}$

Wu, Si, 4P

Wu, Wei, OZ

Wu, Wei-Feng, 13

Wu, Yubin, $2 Y$

Xia, Haojie, 4G

Xiao, Wenbo, 65

Xiao, Xuanlu, 5V

Xiao, Yongjun, 4H, $4 \mathrm{l}$

Xiong, Feibing, 31

Xiong, Yan-ling, 54

$X u$, Boqing, 25, 27

$\mathrm{Xu}$, Sunan, 6C

$X U$, Wei, ON, OT

XU, Xiping, 3D 
$\mathrm{Xu}$, Yishen, 40, 44, 45

$\mathrm{Xu}$, Zhongjie, 5F, 64

Yan, Chao, 6S

Yan, Dan, 5S

Yan, Juncen, 34

Yan, Xingwei, 4M

Yan, Yufeng, 34

Yang, Bingqian, $6 \mathrm{H}$

Yang, Fan, 5T, 5X

Yang, Jun, 6D

Yang, Q., OD

Yang, Qing, 1K, 36

Yang, Shulin, 5S

Yang, Wei-Ping, 47

Yang, Wen-long, 54

Yang, Xiaofei, $1 G$

Yang, Yi, 1D

Yang, Yongjia, 33

Yao, Tianfu, 04, OR, 12, 42, 43, 4M

Ye, Song, 2J

Ye, Wemin, $0 \mathrm{~N}$

Ye, Yan, 44, 45

Ye, Youxiang, $6 \mathrm{~N}$

Yi, Xiao, 4T

Yin, Peng, 3D

Ying, Chaofu, 4F

Young, T. V., 3K

Yu, Xue-lian, 54

Yu, Yang, $5 \mathrm{~S}$

Yuan, Bo, 36

Yuan, Suzhen, 11

Yuan, Xiaodong, ON

Zakoth, David, 28

Zang, Xue-Ping, 13

Zavestovskaya, Irina N., 26

Zghal, M., 18

Zhadin, Alexander, 48

Zhang, Baojun, 4L, 6B, 6E

Zhang, Dongli, 4P

Zhang, Jia-cheng, 54

Zhang, Jian Fa, ON, 2L

Zhang, Jing, $3 X$

Zhang, Jinlong, 33

Zhang, Jun, 4R, 4T

Zhang, Junsheng, $6 \mathrm{H}$

Zhang, Peiming, 4C

Zhang, Pengfei, 3F

Zhang, Qican, 6P

Zhang, Shengyi, 4H, $4 \mathrm{I}$

Zhang, Tao, 6D, 6F

Zhang, Ting, 5A

Zhang, Wanyi, 51

Zhang, Wei, 25

Zhang, Xiao Jie, OM, 29

Zhang, Xiaojun, 6F

Zhang, Xiao-Xiao, 47

Zhang, Xi-Cheng, 20, 26, 3H

Zhang, Xinliang, 1G, $2 Z$

Zhang, Xuexin, 1X, 39

Zhang, Yan, 32, 6C
Zhang, Yang, 47

Zhang, Yang, 5T, 5X, 65, 6D, 6F, 6G

Zhang, Yi, $4 \mathrm{U}$

Zhang, YU, 65

Zhang, Yuhong, 5E

Zhao, Enming, $5 X$

Zhao, Huifu, 3X, 3Y, 46

Zhao, Meng, $4 \mathrm{P}$

Zhao, Peng, 2T

Zhao, Qi, 5K

Zhao, Yancheng, 3C, 6U

Zhao, Yingwei, $\mathrm{OZ}$

Zhao, Yuejin, 10

Zheng, Jiangping, 38

Zheng, Jiaxing, $0 Z$

Zheng, Jihong, 25, 27

Zheng, Lixin, 5Q

Zheng, XiaoDong, OF, OM, OP, 2J, 2R, 5G

Zheng, Yang, 38

Zheng, Zhenrong, $0 Q, 2 \mathrm{~J}$

Zhong, Hairong, OT, 64

Zhou, Feng-qi, 4N

Zhou, J. H., 4 Y

Zhou, Jin-peng, 56

Zhou, Muchun, 5K

Zhou, Xinzhi, 6P

Zhou, Ya, 10, 10

Zhou, Zigang, 33

Zhu, Daqing, $1 \mathrm{~W}$

Zhu, Hao, 4J

Zhu, Jia-Wei, 47

Zhu, Jihua, 5V

Zhu, Jiyan, 25

Zhu, Yuhui, 2J, 35

Zhu, Zheng, 5T, 5X

Zhu, Zhihong, ON

Zhuge, Minghua, 36

Zhukova, Tatiana, 48

Zimmer, Katja, 27

Zou, Rufei, IV

Zubia, Joseba, 16, 49, 4E

Zuidwijk, Thim, 3M 
Proc. of SPIE Vol. 10452 1045201-20 Downloaded From: https://www.spiedigitallibrary.org/conference-proceedings-of-spie on 26 Apr 2023
Terms of Use: https://www.spiedigitallibrary.org/terms-of-use 


\title{
Conference Committee
}

\author{
Conference Chairs
}

Xu Liu, Zhejiang University (China)

Xi-Cheng Zhang, The Institute of Optics, University of Rochester (United States)

Conference Program Committee

Vasudevan Lakshminarayanan, University of Waterloo (Canada) Eugene Arthurs, SPIE

Kathleen Robinson, SPIE

Imrana Ashraf Zahid, Quaid-i-Azam University (Pakistan)

Julie L. Bentley, The Institute of Optics, University of Rochester (United States)

Curtis Burrill, The Optical Society (United States)

Elizabeth Rogan, The Optical Society (United States)

Santiago Camacho-López, Centro de Investigación Científica y de Educación Superior de Ensenada B.C. (Mexico)

Kent D. Choquette, University of Illinois at Urbana-Champaign (United States)

Cristiano Monteiro de Barros Cordeiro, Universidade Estadual de Campinas (Brazil)

Manuel Filipe P. C. M. Martins Costa, Universidade do Minho (Portugal)

Nathalie Debaes, Vrije Universiteit Brussel (Belgium)

Judith F. Donnelly, Retired, Problem Based Learning Projects (United States)

Dirk Fabian, SPIE

Andrew Forbes, University of the Witwatersrand (South Africa)

Ajoy K. Ghatak, Indian Institute of Technology Delhi (India)

Qihuang Gong, Peking University (China)

Guangcan Guo, University of Science and Technology (China)

Jürgen Jahns, FernUniversität in Hagen (Germany)

Pratibha Jolly, University of Delhi (India)

Enock Jonathan, Chinhoyi University of Technology (Zimbabwe)

Hai Ming, University of Science and Technology (China)

Omar Alberto Ormachea, Universidad Privada Boliviana (Bolivia)

Seung-Han Park, Yonsei University (Korea, Republic of)

Thomas Pertsch, Friedrich-Schiller-Universität Jena (Germany)

Monika Raharti, Center for Young Scientists (Indonesia)

Joseph A. Shaw, Montana State University (United States)

K. Alan Shore, Bangor University (United Kingdom)

Daoyin Yu, Tianjin University (China)

María J. Yzuel, Universidad Autònoma de Barcelona (Spain) 
Victor N. Zadkov, M.V. Lomonosov Moscow State University

(Russian Federation)

Mourad Zghal, University of Carthage (Tunisia)

\section{Session Chairs}

ETOP Plenary Session I

Xi-Cheng Zhang, The Institute of Optics, University of Rochester (United States)

ETOP Plenary Session II

Xi-Cheng Zhang, The Institute of Optics, University of Rochester (United States)

Curriculum Development in Optics and Photonics Education I Imrana Ashraf Zahid, Quaid-i-Azam University (Pakistan)

New Pedagogical Methods, Tools and Models in Optical Education I Mourad Zghal, Univeristy of Carthage (Tunisia)

Laboratories for Optics Education I

Monika Raharti, Center for Young Scientists (Indonesia)

New Pedagogical Methods, Tools and Models in Optical Education II

Andrew J. Berger, The Institute of Optics, University of Rochester (United States)

Khaled J. Habib, Kuwait Institute for Scientific Research (Kuwait)

Laboratories for Optics Education II

Michael Vollmer, Technische Hochschule Brandenburg (Germany)

Jephias Gwamuri, Michigan Technological University (United States)

Education and Training for Multidisciplinary Education II

Michael Wick, Hochschule für Angewandte Wissenschaften und Kunste (Germany)

Digital and Internet Technology for Optical Education

Aaron J. Danner, National University of Singapore (Singapore)

International Exchange and Cooperation for Optical Education

Ahmadou Wague, University Cheikh Anta Diop de Dakar (Senegal)

ETOP Keynote Session I

H. Paul Urbach, Technische Universeit Delft (Netherlands)

Curriculum Development in Optics and Photonics Education III

Mourad Zghal, Univeristy of Carthage (Tunisia) 
New Pedagogical Methods, Tools and Models in Optical Education III Imrana Ashraf Zahid, Quaid-i-Azam University (Pakistan)

Laboratories for Optics Education III

Monika Raharti, Center for Young Scientists (Indonesia)

Training Programs for Senior Undergraduates

Joseph A. Shaw, Montana State University (United States)

Curriculum Development in Optics and Photonics Education IV

Julie L. Bentley, The Institute of Optics, University of Rochester (United States)

New Pedagogical Methods, Tools and Models in Optical Education IV Imrana Ashraf Zahid, Quaid-i-Azam University (Pakistan)

Enock Jonathan, Chinhoyi University of Technology (Zimbabwe)

Laboratories for Optics Education IV

Xiaodong Zheng, Zhejiang University (China)

ETOP Keynote Session II

Xu Liu, Zhejiang University (China)

ETOP Keynote Session III

Xu Liu, Zhejiang University (China) 
Proc. of SPIE Vol. 10452 1045201-24

Downloaded From: https://www.spiedigitallibrary.org/conference-proceedings-of-spie on 26 Apr 2023 Terms of Use: https://www.spiedigitallibrary.org/terms-of-use 


\section{Introduction}

The 14th Conference on Education and Training in Optics and Photonics: ETOP 2017 was held at Zhejiang University, Hangzhou, China, on 29-31 May 2017. The conference gathered 286 educators in the areas of optics and photonics from 28 countries and regions.

This was the first ETOP conference held in China after its founding in 1988, and the largest ETOP conference by the number of participants and presentations.

ETOP 2017 brought together leading optics and photonics educators from all levels and orientations to discuss, demonstrate, and learn about new developments and approaches of teaching in their fields. Through presentations, panel discussions, workshops and exhibits, it was the intent of this conference to inform professors, students, teachers, and professional trainers on how to teach optics and photonics for the future.

The teaching of optics and photonics, critical fields at the core of today's worldwide technological infrastructure, must continually get evaluated and improved in order to meet the growing demands of research, science, and industry.

We had a very successful ETOP meeting. The number of submissions (both of published papers and of abstracts for the program) have set the new record in the history of the conference.

Xu Liu

Xi-Cheng Zhang 
Proc. of SPIE Vol. 10452 1045201-26 Downloaded From: https://www.spiedigitallibrary.org/conference-proceedings-of-spie on 26 Apr 2023
Terms of Use: https://www.spiedigitallibrary.org/terms-of-use 